\title{
Gestational diabetes: screening uptake, current challenges and the future - a focused review
}

\author{
ELPIDA VOUNZOULAKI, ${ }^{1}$ KAMLESH KHUNTI, ${ }^{1}$ BEE K TAN, ${ }^{2}$ MELANIE J DAVIES, ${ }^{3}$ CLARE L GILLIES ${ }^{1}$
}

\begin{abstract}
The increased risk of developing type 2 diabetes mellitus (T2DM) in women with a history of previous gestational diabetes mellitus (GDM) has been established and is well recognised. Post-partum screening for T2DM is essential to identify those at higher risk and allow for the implementation of preventative interventions. However, attendance rates for postpartum glucose screening in women with previous GDM remain substantially low, with only half of them attending screening. This review aimed to outline the National Institute for Health and Care Excellence (NICE) post-partum screening recommendations and compare them with the guidelines being used worldwide, provide information on post-partum screening uptake and possible determinants of uptake in the UK, and to briefly discuss both patient health implications and the financial burden associated with T2DM progression in the context of the National Health Service (NHS).
\end{abstract}

Br J Diabetes 2020;20:9-14

Key words: gestational diabetes mellitus, type 2 diabetes mellitus, post-partum screening, United Kingdom

\section{Background}

Gestational diabetes mellitus (GDM) is a relatively common pregnancy complication, defined as glucose intolerance with onset or first diagnosis during the second or third trimester of pregnancy, that is clearly not either pre-existing type 1 or type 2 diabetes mellitus (T2DM). ${ }^{1}$ In 2019 the International Diabetes Federation

Department of Health Sciences, University of Leicester, Leicester; Diabetes Research Centre, Leicester General Hospital, University of Leicester, Leicester; National Institute for Health Research (NIHR) Applied Research Collaboration-East Midlands (ARC-EM), Leicester Diabetes Centre, Leicester, UK

2 Department of Cardiovascular Sciences, University of Leicester, Leicester, UK

Department of Health Sciences, Diabetes Research Centre and National Institute for Health Research (NIHR) Leicester Biomedical Research Centre (BRC), Leicester General Hospital, Leicester, UK

Address for correspondence: Ms Elpida Vounzoulaki Department of Health Sciences, University of Leicester, Leicester

LE1 7RH, UK

E-mail: ev63@le.ac.uk

https://doi.org/10.15277/bjd.2020.236 estimated that, on a global scale, hyperglycaemia in pregnancy affects 20.4 million or $15.8 \%$ of live births, with $83.6 \%$ of these cases being due to GDM. ${ }^{2}$ A diagnosis of GDM during pregnancy has been associated with a considerable number of adverse maternal and perinatal outcomes. ${ }^{3}$ Although it is a pregnancy complication that usually resolves following labour, GDM carries a lifetime risk of up to $60 \%$ for developing T2DM, being regarded as a natural opportunity to screen for future T2DM. ${ }^{4}$ The effectiveness of preventative interventions for T2DM in women with a known history of GDM has been well established, ${ }^{5}$ while post-partum screening for T2DM is essential to identify those at higher risk and allow for the implementation of these interventions. However, the rates of post-partum glucose screening in women with previous GDM remain substantially low, with only half of them attending screening. ${ }^{6}$ Meanwhile, the prevalence of both GDM and T2DM is on the rise, with 463 million (9.3\% of the global population) currently living with diabetes, and with these numbers expected to reach up to 700 million $(10.9 \%)$ by 2045.2

This narrative review aimed to outline the National Institute for Health and Care Excellence (NICE) post-partum screening recommendations and compare them with the guidelines being used worldwide, provide detailed information on post-partum screening uptake and possible determinants of uptake in the UK by synthesising evidence from the existing literature, and to briefly discuss both patient future health implications and the financial burden associated with T2DM progression in the context of the National Health Service (NHS).

\section{Methods}

A literature search for studies on T2DM screening uptake following GDM was conducted using Ovid MEDLINE, PubMed and Google Scholar. Databases were searched from 2000 to 2019 and search terms included gestational diabetes, type 2 diabetes, post-partum screening and United Kingdom. All reference lists from relevant studies were hand-searched for any additional eligible studies.

\section{Results}

Screening recommendations and postnatal care

The NICE guidelines state that, following labour, women affected by GDM during pregnancy should be offered lifestyle advice, including diet and exercise, and are recommended to undergo a fasting plasma glucose (FPG) test. ${ }^{7}$ The FPG test should be performed at 6-13 weeks post-partum, although in cases where it has not been performed by 13 weeks, either this test or a glycated 
Figure 1. Risk classification of type 2 diabetes mellitus (T2DM) in women with previous gestational diabetes mellitus as recommended by NICE

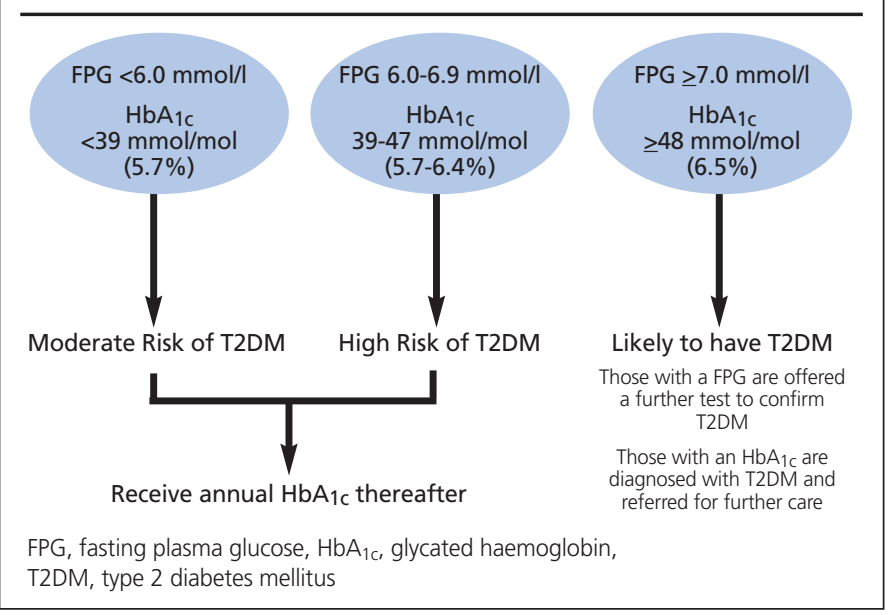

haemoglobin $\left(\mathrm{HbA}_{1 \mathrm{c}}\right)$ test can be performed after 13 weeks. $^{7}$ Women with previous GDM who receive a negative post-partum test result for T2DM should be offered an annual $\mathrm{HbA}_{1 \mathrm{c}}$ test. ${ }^{7} \mathrm{NICE}$ additionally recommends that the $75 \mathrm{~g}$ 2-hour oral glucose tolerance test (OGTT) should not be routinely performed for women with previous GDM, with normal blood glucose levels following labour. ${ }^{7}$

Based on the result of the post-partum screening test performed, women are categorised as having a moderate or high risk of developing T2DM in the future, or as likely to have T2DM (see Figure 1). ${ }^{7}$
Screening recommendations by international guidelines

The NICE screening recommendations in the UK have been outlined in detail in the previous section and are presented in Table 1, along with all international guidelines released to date. While both NICE and the American College of Obstetricians and Gynaecologists $(\mathrm{ACOG})^{8}$ recommend the FPG for early post-partum screening, the American Diabetes Association (ADA) ${ }^{9}$, the Recommendations of the 5th International Workshop-Conference on Gestational Diabetes Mellitus, ${ }^{10}$ the Canadian Diabetes Association (CDA), ${ }^{11}$ the Royal Australian College of General Practitioners (RACGP) $)^{12}$ and the Australasian Diabetes in Pregnancy Society (ADIPS) ${ }^{13}$ suggest the $75 \mathrm{~g}$ 2-hour OGTT, focusing on its sensitivity in glucose intolerance detection for both prediabetes and T2DM. The lack of universal post-partum screening guidelines for T2DM highlights the uncertainty surrounding best clinical practice for post-partum screening after GDM.

The $75 \mathrm{~g}$ 2-hour OGTT is considered the gold standard test for the diagnosis of post-partum T2DM by the majority of international guidelines. It has been shown that, compared with both FPG and $\mathrm{HbA}_{1 \mathrm{c}}$, the $75 \mathrm{~g}$ 2-hour OGTT can detect more cases of both prediabetes and T2DM. ${ }^{14}$ A study by Kousta et al showed that postpartum screening for T2DM in women with previous GDM using a single FPG value lacks sensitivity for detecting abnormal glucose tolerance. ${ }^{15}$ Additionally, a more recent study by Kim et al investigated the ability of isolated $\mathrm{HbA}_{1 \mathrm{c}}$ with a cut-off value equal to or above $5.7 \%$ (39 mmol/mol) and found that it had poor sensitivity and specificity in detecting abnormal glucose tolerance. ${ }^{16}$ However, from a patient perspective, published systematic reviews assessing women's views on barriers to post-partum screening have identified the OGTT as a significant barrier - being inconvenient, unpleasant

Table 1 Post-partum screening guidelines for T2DM for women with previous GDM

\begin{tabular}{|c|c|c|c|c|c|c|c|}
\hline & UK NICE7 & $\mathrm{ADA}^{9}$ & $\mathrm{ACOG}^{8}$ & 5th IWCGDM ${ }^{10}$ & $\mathrm{CDA}^{11}$ & RACGP $^{12}$ & ADIPS $^{13}$ \\
\hline 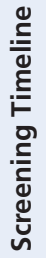 & $\begin{array}{l}\text { 6-13 weeks PP; } \\
\text { if normal, } \\
\text { annually }\end{array}$ & $\begin{array}{l}\text { 4-12 weeks PP; } \\
\text { if normal, every } \\
1-3 \text { years } \\
\text { frequency } \\
\text { depending on } \\
\text { risk factors* }\end{array}$ & $\begin{array}{l}\text { 4-12 weeks PP; } \\
\text { if normal, every } \\
\text { 1-3 years; if IFG } \\
\text { or IGT or both, } \\
\text { annually }\end{array}$ & 6-12 weeks PP & $\begin{array}{l}6 \text { weeks-6 } \\
\text { months PP }\end{array}$ & $\begin{array}{l}6-12 \text { weeks PP; } \\
\text { every } 3 \text { years }\end{array}$ & 6-12 weeks PP \\
\hline 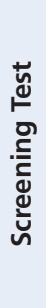 & $\begin{array}{l}\text { FPG, } \mathrm{HbA}_{1 \mathrm{c}} \\
\text { (13 weeks PP } \\
\text { and on) } \\
\text { (75 g 2-hour } \\
\text { OGTT not } \\
\text { recommended) }\end{array}$ & $\begin{array}{l}75 \text { g 2-hour } \\
\text { OGTT }\left(\mathrm{HbA}_{1 \mathrm{c}}\right. \\
\text { not recommended } \\
\text { at } 4-12 \text { weeks PP) } \\
\text { Ongoing } \\
\text { evaluation with } \\
\mathrm{HbA}_{1 \mathrm{c}}, \mathrm{FPG} \text {, } \\
75 \mathrm{~g} \mathrm{2h} \mathrm{OGTT}\end{array}$ & $\begin{array}{l}\text { FPG or } 75 \mathrm{~g} \\
\text { 2-hour OGTT }\end{array}$ & $\begin{array}{l}75 \mathrm{~g} \text { 2-hour } \\
\text { OGTT }\end{array}$ & $\begin{array}{l}75 \mathrm{~g} \text { 2-hour } \\
\text { OGTT }\end{array}$ & $\begin{array}{l}75 \text { g } 2 \text {-hour } \\
\text { OGTT } \\
\text { FPG or } \mathrm{HbA}_{1 \mathrm{c}} \\
\text { (every } 3 \text { years) }\end{array}$ & $\begin{array}{l}75 \mathrm{~g} \text { 2-hour } \\
\text { OGTT }\end{array}$ \\
\hline $\begin{array}{l}\text { AC } \\
C D \\
\text { IGT } \\
\text { RA }\end{array}$ & $\begin{array}{l}\text { rican College of } \mathrm{C} \\
\text { dian Diabetes Asso } \\
\text { d glucose toleranc } \\
\text { al Australian Colle }\end{array}$ & $\begin{array}{l}\text { tricians and Gynaecol } \\
\text { on; FPG, fasting plasm } \\
\text { VCGDM, International } \\
\text { f General Practitioners }\end{array}$ & $\begin{array}{l}\text { ists; ADA, Americar } \\
\text { glucose; GDM, gest } \\
\text { lorkshop-Conferenc } \\
\text { 2DM, type } 2 \text { diabe }\end{array}$ & $\begin{array}{l}\text { etes Association; A } \\
\text { l diabetes mellitus; } \\
\text { Gestational Diabete } \\
\text { ellitus. }\end{array}$ & $\begin{array}{l}\text { Australasian Di } \\
\text { c, glycated hae } \\
\text { itus; OGTT, ora }\end{array}$ & $\begin{array}{l}\text { es in Pregnancy Socie } \\
\text { lobin; IFG, impaired } \\
\text { cose tolerance test; } P\end{array}$ & $\begin{array}{l}\text { ting glucose; } \\
\text { oost-partum; }\end{array}$ \\
\hline
\end{tabular}


and time-consuming - and supported the view that a quicker test could have facilitated attendance. ${ }^{17,18} \mathrm{~A}$ further qualitative study by Eborall et al demonstrated that these views were consistent beyond the scope of post-partum screening in a broader population of individuals at potential risk of T2DM. ${ }^{19}$

Acknowledging the aforementioned association of the $75 \mathrm{~g}$ 2-hour OGTT with poor screening uptake, Noctor et al investigated the efficacy of the FPG and $\mathrm{HbA}_{1 c}$ tests, or a combination of both, in the diagnosis of post-partum T2DM. ${ }^{20}$ They found that the combination of the cut-offs of FPG $5.6 \mathrm{mmol} / \mathrm{L}$ and $\mathrm{HbA}_{1 \mathrm{c}} 39 \mathrm{mmol} / \mathrm{mol}$ was capable of identifying $90 \%$ of women with abnormal postpartum glucose tolerance, and implementing this strategy will potentially lead to improved long-term post-partum screening uptake. ${ }^{20}$ The $\mathrm{HbA}_{1 \mathrm{c}}$ is associated with several advantages over the OGTT as there is no need for fasting prior to receiving the test or ingesting a glucose load, while timed samples are not required. ${ }^{21,22}$ Additionally, $\mathrm{HbA}_{1 \mathrm{c}}$ is not importantly affected by any derangements in glucose levels associated with conditions such as stress or acute illness. ${ }^{21,22}$ However, it must be noted that the $\mathrm{HbA}_{1 \mathrm{c}}$ assay can be affected by the increased red blood cell turnover related to pregnancy ${ }^{9}$ or by certain common post-partum conditions such as iron deficiency or acute blood loss, but this requires further investigation. ${ }^{16}$

The lack of consensus on post-partum screening for T2DM between existing guidelines is responsible for introducing multiple challenges in patient care. Apart from post-partum screening, there are also important inconsistencies regarding the diagnostic strate- gies for GDM being used during pregnancy. ${ }^{23}$ Due to differences in both the approach (one-step versus two-step) as well as the diagnostic cut-off values for GDM, different guidelines identify slightly different patient cohorts, who then receive counselling and are recommended to undergo post-partum screening. Hence, there is a possibility that an important number of high-risk individuals are missed by guidelines using a higher diagnostic cut-off in pregnancy. The use of the OGTT for post-partum T2DM screening is associated with an important time barrier and could potentially be responsible for introducing health inequalities between women with a history of GDM from lower socioeconomic backgrounds, as the latter are less likely to afford a day off work or childcare and are therefore more likely to not attend screening. ${ }^{19}$ The $\mathrm{HbA}_{1 \mathrm{c}}$ is a promising approach that should be considered, but more research is needed to determine the efficacy and cost-effectiveness of this test in the long term.

\section{Screening uptake}

All studies retrieved by our literature search demonstrated that postpartum screening uptake in women with a history of GDM in the UK is low and can be attributed to several factors, a fact that is consistent with findings from published systematic reviews. ${ }^{17,24}$ Table 2 shows the key studies listed in chronological order.

A national survey of both hospitals and general practices by Pierce et al demonstrated that there is lack of long-term follow-up for women with previous GDM, and that $80 \%$ of secondary care specialists and $30 \%$ of general practitioners (GPs) performed an

Table 2 Studies reporting post-partum screening rates and determinants in the UK

\begin{tabular}{|c|c|c|c|}
\hline Study (author, year) & Study design & No of patients/responders & Key findings \\
\hline $\begin{array}{l}\text { Walsh et al, } \\
2019^{28}\end{array}$ & Cohort & $\begin{array}{l}535 \text { (pre-guidance } n=306 \\
\text { post-guidance } n=229) \\
(\text { GDM) }\end{array}$ & $\begin{array}{l}\text { Follow-up rates improved from } 60.5 \% \text { to } 69.9 \% \text { after the release of } \\
\text { updated NICE guidance, while over a third of women with GDM were } \\
\text { not followed up }\end{array}$ \\
\hline $\begin{array}{l}\text { Carmody et al, } \\
2015^{29 *}\end{array}$ & $\begin{array}{l}\text { Prospective } \\
\text { cohort }\end{array}$ & 1520 (GDM) & $\begin{array}{l}\text { Introducing a central coordinator to remind women about post-partum } \\
\text { screening can achieve rates of } 75 \% \\
\text { Older women and those who have used insulin for the management of } \\
\text { GDM during pregnancy more likely to attend screening }\end{array}$ \\
\hline $\begin{array}{l}\text { Pierce et al, } \\
2011^{25}\end{array}$ & $\begin{array}{l}\text { Nationwide } \\
\text { postal survey }\end{array}$ & 915 GPs, 342 specialists & $\begin{array}{l}80 \% \text { of GPs and } 98 \% \text { of specialists reported that women with GDM had } \\
\text { short-term follow-up } \\
73 \% \text { of specialists recommended long-term follow-up and 39\% of GPs } \\
\text { recalled women for that } \\
80 \% \text { of specialists and } 30 \% \text { of GPs used OGTTs instead of FPGs for } \\
\text { short-term follow-up }\end{array}$ \\
\hline
\end{tabular}


OGTT rather than a FPG test for short-term post-partum follow-up, despite the NICE recommendations. ${ }^{25}$ The authors additionally reported that short-term follow-up in this population was sufficient, ${ }^{25}$ but these results need to be carefully interpreted because of the nature of this study. A retrospective cohort study in 127 primary care practices in the UK by McGovern et al reported short-term follow-up of 18.5\% and long-term follow-up of around $20 \%$ over a 5 -year period. ${ }^{26}$ They also reported that Asian women were more likely to attend long-term follow-up. ${ }^{26}$ Similarly, the recent cross-sectional analysis by Fahami et al showed that only 38\% of women with previous GDM received screening for T2DM up to 13 weeks post-partum, while only $16 \%$ of them received an annual $\mathrm{HbA} 1 \mathrm{c}$ test. ${ }^{27}$ The study additionally identified a significant association between South Asian ethnicity and poor uptake to annual screening. ${ }^{27}$ Following the release of the updated NICE guidelines in 2015 recommending routine follow-up, Walsh et al compared post-partum follow-up rates before and after the update. ${ }^{28}$ They found that the rate of post-partum follow-up improved from $60.5 \%$ to $69.9 \%$, suggesting that the use of the $\mathrm{HbA}_{1 \mathrm{c}}$ is potentially responsible. ${ }^{28}$ However, although uptake improved, over a third of the study population were still not followed up. ${ }^{28}$

In an attempt to improve regional post-partum screening attendance, Carmody et al demonstrated that the implementation of a central coordinator responsible for reminding women about the importance of screening could effectively achieve screening attendance rates of $75 \% .{ }^{29}$ Finally, Curtis et al showed that early post-partum glycaemic assessment with a FPG performed before hospital discharge was associated with a total uptake of $94.9 \%$, and is therefore an effective strategy to increase screening uptake in women with previous GDM..$^{30}$ While this is a relatively new strategy for post-partum glucose screening, the authors suggested that these results would not be much different to those of the 6-week post-partum testing recommended by NICE. ${ }^{30}$ The subsequent follow-up of women with previous GDM should still remain a priority, while the validity of this strategy needs to be further evaluated by studies on larger populations. ${ }^{30}$

Women with a history of GDM are high-risk individuals who require a consistent, patient-centred approach and management. Previous surveys assessing views of women with a history of GDM on post-partum screening have identified time restrictions and child responsibilities as key determinants of poor post-partum screening attendance. ${ }^{31-33}$ There is an overall lack of awareness and low risk perception for future T2DM in this patient group, ${ }^{31,33}$ indicating major gaps in communication between healthcare professionals and patients as well as poor patient education. There is also a lack of public health commissioned services targeting women with previous GDM by focusing on their individual needs, which has an important impact on screening attendance. ${ }^{34,35}$

\section{Progression to T2DM and future impact}

There have been several studies in the UK examining T2DM progression in women with previous GDM. A study in the Dundee and Angus region of Scotland by Eades et al demonstrated that $25 \%$ of women with previous GDM developed T2DM during a mean follow-up period of 8 years, and identified increased preg- nancy weight, use of insulin for management of GDM and higher $\mathrm{HbA}_{1 \mathrm{c}}$ and FPG levels at diagnosis of GDM as the main factors associated with increased progression. ${ }^{36} \mathrm{~A}$ retrospective cohort using data from a primary care database in the UK showed that women with GDM were over 20 times more likely to be diagnosed with T2DM compared with healthy controls. ${ }^{37}$ Similarly, another study investigating the impact of ethnicity on progression showed that impaired glucose regulation or T2DM was present in 37\% of women with previous GDM, with rates being higher in nonEuropean women. ${ }^{38}$

Other than T2DM, women with previous GDM are more likely to develop cardiovascular disease or be diagnosed with nonalcoholic fatty liver disease, ${ }^{39,40}$ conditions that contribute to a significant reduction in average life expectancy. When it comes to patient perception about their overall quality of life, Dalfra et al found that women with GDM had a poor perception of their general health during pregnancy, and following labour they had worse symptoms of depression. ${ }^{41}$

According to an analysis of data from a cluster-randomised trial, a diagnosis of GDM has been associated with 25\% higher healthcare costs, with both the cost of inpatient visits and the use of neonatal intensive care unit being over $40 \%$ higher in women with GDM compared with those not diagnosed with GDM. ${ }^{42}$ For the NHS, annual costs for blood glucose-lowering medication have exceeded $\mathrm{f} 1$ billion, ${ }^{43}$ while it is expected that the overall cost of diabetes will account for $17 \%$ of the NHS total expenditure by 2035.44

The early identification and prevention of T2DM in women affected by GDM during pregnancy should be regarded as an immediate priority. As a diagnosis of GDM serves as an opportunity to target high-risk individuals, it is important to build effective strategies to engage with this patient group. Healthcare professionals should provide these women with counselling and prioritise them for preventative interventions, using a patient-centred approach that accounts for the additional challenges motherhood brings.

\section{Conclusions}

This review highlights that, regardless of all the evidence, the uptake of both short-and long-term post-partum T2DM screening in women with previous GDM is low in the UK. This trend is consistent on a global scale, as several studies from European countries, the USA and Canada have similarly reported that the majority of women with previous GDM do not adhere with post-partum screening for T2DM. ${ }^{45-48}$ Personal factors as well as factors associated with the healthcare system are likely to influence post-partum screening attendance. Therefore, there is an urgent need to improve women's understanding about the subsequent risk of T2DM following a diagnosis of GDM in pregnancy, while changes are required in healthcare provision to reduce barriers to postpartum screening and improve screening attendance. ${ }^{49}$

The implementation of post-partum screening reminders is recognised as an effective strategy to improve screening..$^{50-52} \mathrm{How}$ ever, the results of studies assessing the effectiveness of screening reminders are mixed, ${ }^{53}$ while there is a lack of large randomised 


\section{Key messages}

- There is strong evidence supporting the necessity of post-partum screening for type 2 diabetes in women diagnosed with gestational diabetes during pregnancy

- Both short-term and long-term post-partum screening for type 2 diabetes is suboptimal in the UK and worldwide, with only half of these women attending screening

- Barriers to screening include time restrictions, child responsibilities, low risk perception, poor patientphysician communication, as well as the nature of the oral glucose tolerance test

- Future research should focus on identifying the most accurate, efficient, timely and convenient post-partum screening test for type 2 diabetes

controlled trials investigating outcomes in heterogeneous populations. The use of screening reminders recommending child examinations combined with post-partum screening could potentially be successful in reducing barriers and improving screening attendance..$^{53}$ In addition, it has been suggested that the focus of health visiting services, which is currently centred on children's health, could be extended to maternal health as well, to encourage more women to attend screening. ${ }^{35}$

While both the timing of screening and the type of screening test used can have an impact on screening attendance, as discussed in this review, there is no consensus between universal guidelines on the optimal test and timing of screening. The advantages of routine follow-up of women with GDM are profound as ongoing risk factors for future T2DM could be identified and optimised. ${ }^{28}$ Future research needs to focus on identifying the most accurate, timely and convenient screening test, assessing both the efficacy and associated costs. As the need for long-term screening in this highrisk population is still unmet, large studies with long-term followup are required to investigate both determinants of post-partum screening attendance and how attendance rates can be increased.

Conflict of interest KK has acted as a consultant and speaker for Novartis, Novo Nordisk, Sanofi-Aventis, Lilly, Servier and Merck Sharp \& Dohme. He has received grants in support of investigator and investigator-initiated trials from Novartis, Novo Nordisk, Sanofi-Aventis, Lilly, Pfizer, Boehringer Ingelheim and Merck Sharp \& Dohme. He has received funds for research, honoraria for speaking at meetings and has served on advisory boards for Lilly, Sanofi-Aventis, Merck Sharp \& Dohme and Novo Nordisk. MJD has acted as consultant, advisory board member and speaker for Novo Nordisk, Sanofi-Aventis, Lilly, Merck Sharp \& Dohme, Boehringer Ingelheim, AstraZeneca and Janssen and as a speaker for Mitsubishi Tanabe Pharma Corporation. She has received grants in support of investigator and investigator-initiated trials from Novo Nordisk, Sanofi-Aventis and Lilly. All other authors declare there is no duality of interest in connection with their involvement in this study.

Funding None
Acknowledgements This research is supported by the National Institute for Health Research (NIHR) Applied Research Collaboration East Midlands (ARC EM) and the NIHR Leicester Biomedical Research Centre (BRC). The views expressed are those of the author(s) and not necessarily those of the NIHR, NHS or the Department of Health and Social Care.

\section{References}

1. American Diabetes Association (ADA). Classification and diagnosis of diabetes: Standards of medical care in diabetes 2019. Diabetes Care 2019;42(January):13-28. https://doi.org/10.2337/dc19-S002

2. International Diabetes Federation. IDF Diabetes Atlas, 9th edn. Brussels, Belgium, 2019. https://www.diabetesatlas.org

3. The HAPO Study Cooperative Research Group. Hyperglycemia and adverse pregnancy outcomes. N Engl J Med 2008;358(19):1991-2002. https://doi.org/10.1056/NEJMoa0707943

4. Noctor E. Type 2 diabetes after gestational diabetes: The influence of changing diagnostic criteria. World J Diabetes 2015;6(2):234-44. https://doi.org/10.4239/wjd.v6.i2.234

5. Morton S, Kirkwood S, Thangaratinam S. Interventions to modify the progression to type 2 diabetes mellitus in women with gestational diabetes. Curr Opin Obstet Gynecol 2014;26(6):476-86. https://doi.org/ 10.1097/gco.0000000000000127

6. Tovar A, Chasan-Taber L, Eggleston E, Oken E. Postpartum screening for diabetes among women with a history of gestational diabetes mellitus. Prev Chronic Dis 2011;8(6):A124. http://www.cdc.gov/pcd/ issues/2011/nov/11_0031.htm

7. National Institute for Health and Care Excellence (NICE). Diabetes in pregnancy: management from preconception to the postnatal period. February 2015. https://www.nice.org.uk/guidance/ng3

8. American College of Obstetricians and Gynecologists (ACOG). Practice Bulletin No. 190: Gestational Diabetes Mellitus. Obstet Gynecol 2018;131(2). https://doi/org/10.1097/AOG.0000000000002501

9. American Diabetes Association (ADA). Management of diabetes in pregnancy: Standards of medical care in diabetes 2019. Diabetes Care 2019;42(January):S165-72. https://doi.org/10.2337/dc19-S014

10. Metzger BE, Buchanan TA, Coustan DR, et al. Summary and recommendations of the Fifth International Workshop-Conference on Gestational Diabetes Mellitus. Diabetes Care 2007;30(Suppl 2). https://doi.org/ 10.2337/dc07-s225

11. Feig DS, Berger H, Donovan L. 2018 Clinical Practice Guidelines. Diabetes and Pregnancy. Diabetes Canada Clinical Practice Guidelines Expert Committee. Can J Diabetes 2018;42:255-82.

12. Royal Australian College of General Practitioners. General practice management of type 2 diabetes. Diabetes Australia 2016.

13. Nankervis A, Mclntyre HD, Moses R, et al. ADIPS consensus guidelines for the testing and diagnosis of hyperglycaemia in pregnancy in Australia and New Zealand. 2014(November):1-8. http://www.adips.org/ downloads/2014ADIPSGDMGuidelinesV18.11.2014_000.pdf

14. Meijnikman AS, De Block CEM, Dirinck E, et al. Not performing an OGTT results in significant underdiagnosis of (pre)diabetes in a high risk adult Caucasian population. Int J Obes 2017:41(11):1615-20. http://dx.doi.org/10.1038/ijo.2017.165

15. Kousta E, Lawrence NJ, Penny A, et al. Implications of new diagnostic criteria for abnormal glucose homeostasis in women with previous gestational diabetes. Diabetes Care 1999;22(6):933-7. https://doi.org/ 10.2337/diacare.22.6.933

16. Kim C, Herman WH, Cheung NW, Gunderson EP, Richardson C. Comparison of hemoglobin A $1 \mathrm{c}$ with fasting plasma glucose and 2-h postchallenge glucose for risk stratification among women with recent gestational diabetes mellitus. Diabetes Care 2011;34(9):1949-51. https://doi.org/10.2337/dc11-0269

17. Sanderson H, Loveman E, Colquitt J, Royle P, Waugh N, Tan B. Improving uptake of postnatal checking of blood glucose in women who had gestational diabetes mellitus in universal healthcare settings: a systematic review. J Clin Med 2018;8(1):4. http://dx.doi.org/10.3390/jcm8010004

18. Van Ryswyk E, Middleton P, Shute E, Hague W, Crowther C. Women's views and knowledge regarding healthcare seeking for gestational diabetes in the postpartum period: a systematic review of qualitative/ survey studies. Diabetes Res Clin Pract 2015;110(2):109-22. 
https://doi.org/10.1016/j.diabres.2015.09.010

19. Eborall H, Stone M, Aujla N, Taub N, Khunti K, Davies M. Influences on the uptake of diabetes screening: A qualitative study in primary care. $\mathrm{Br}$ J Gen Pract 2012;62(596):204-11. http://dx.doi.org/10.3399/ bjgp12X630106

20. Noctor E, Crowe C, Carmody LA, et al. ATLANTIC DIP: Simplifying the follow-up of women with previous gestational diabetes. Eur J Endocrinol 2013;169(5):681-7. http://dx.doi.org/10.1530/EJE-13-0491

21. International Expert Committee. Report on the role of the $\mathrm{A} 1 \mathrm{C}$ assay in the diagnosis of diabetes. Diabetes Care 2009;32(7):1327-34. http://dx.doi.org/10.2337/dc09-9033

22. Mostafa SA, Davies MJ, Srinivasan BT, Carey ME, Webb D, Khunti K. Should glycated haemoglobin ( $\mathrm{HbA1c}$ ) be used to detect people with type 2 diabetes mellitus and impaired glucose regulation? Postgrad Med J 2010;86(1021):656-62. http://dx.doi.org/10.1136/pgmj.2009.091215

23. Li-Zhen L, Yun X, Xiao-Dong Z, et al. Evaluation of guidelines on the screening and diagnosis of gestational diabetes mellitus: systematic review. BMJ Open 2019;9(5):e023014. http://dx.doi.org/10.1136/ bmjopen-2018-023014

24. Nielsen KK, Kapur A, Damm P, de Courten M, Bygbjerg IC. From screening to postpartum follow-up - the determinants and barriers for gestational diabetes mellitus (GDM) services, a systematic review. BMC Pregnancy Childbirth 2014:14(1). http://dx. doi.org/10.1186/1471-2393-14-41

25. Pierce M, Modder J, Mortagy I, Springett A, Hughes H. Missed opportunities for diabetes prevention. Br J Gen Pract 2011;61(591):e611-9. https://doi.org/10.3399/bjgp11X601316

26. McGovern A, Butler $L$, Jones $S$, et al. Diabetes screening after gestational diabetes in England. Br J Gen Pract 2014;64(618):e17-23. https://doi.org/10.3399/bjgp14X676410

27. Fahami R, Dhalwani N, Khunti K, Davies M, Seidu S. Postpartum monitoring of women with a history of gestational diabetes - a cross-sectional study of an inner-city population. Prim Care Diabetes 2019;13(4):3769. https://doi.org/10.1016/j.pcd.2018.11.010

28. Walsh S, Htun H, Hodgett S, Barton D. A comparison of follow-up rates of women with gestational diabetes before and after the updated National Institute for Health and Care Excellence guidance advocating routine follow-up, and the association with neighbourhood deprivation. Br J Diabetes 2019:19:14-8. https://doi.org/10.15277/bjd.2019.202

29. Carmody L, Egan AM, Dunne FP. Postpartum glucose testing for women with gestational diabetes mellitus: Improving regional recall rates. Diabetes Res Clin Pract 2015;108(3):e38-41. http://dx.doi.org/10.1016/ j.diabres.2015.04.005

30. Curtis L, Burgess C, McCord N, Masding MG. Early postpartum glycaemic assessment in patients with gestational diabetes. Pract Diabetes 2017;34(3):89-91. https://doi.org/10.1002/pdi.2089

31. Minsart AF, Vander Maelen A, Fontaine V, Kirkpatrick C. Social, medical and self-perceived factors influencing postpartum screening of diabetes after gestational diabetes. J Obstet Gynaecol (Lahore) 2014;34(1):8-12. http://dx.doi.org/10.3109/01443615.2013.826639

32. Van Ryswyk EM, Middleton PF, Hague WM, Crowther CA. Women's views on postpartum testing for type 2 diabetes after gestational diabetes: six month follow-up to the DIAMIND randomised controlled trial. Prim Care Diabetes 2016;10(2):91-102. https://doi.org/10.1016/ j.pcd.2015.07.003

33. Sterne $V$, Logan T, Palmer MA. Factors affecting attendance at postpartum diabetes screening in women with gestational diabetes mellitus. Pract Diabetes Int 2011;28(2):64-9. http://dx.doi.org/10.1002/pdi.1559

34. Lie MLS, Hayes L, Lewis-Barned NJ, May C, White M, Bell R. Preventing type 2 diabetes after gestational diabetes: women's experiences and implications for diabetes prevention interventions. Diabet Med 2013: 30(8):986-93. https://doi.org/10.1111/dme.12206

35. Plant N, Šumilo D, Chapman R, Webber J, Saravanan P, Nirantharakumar $K$. Unmet needs of women with GDM: a health needs assessment in Sandwell, West Midlands. J Public Health 2019;1-9. https://doi.org/ 10.1093/pubmed/fdz172

36. Eades CE, Styles M, Leese GP, Cheyne H, Evans JMM. Progression from gestational diabetes to type 2 diabetes in one region of Scotland: an observational follow-up study. BMC Pregnancy Childbirth 2015;15(1):1-6. http://dx.doi.org/10.1186/s12884-015-0457-8
37. Daly B, Toulis KA, Thomas N, et al. Increased risk of ischemic heart disease, hypertension, and type 2 diabetes in women with previous gestational diabetes mellitus, a target group in general practice for preventive interventions: a population-based cohort study. PLoS Med 2018;15(1). http://dx.doi.org/10.1371/journal.pmed.1002488

38. Kousta E, Efstathiadou Z, Lawrence NJ, et al. The impact of ethnicity on glucose regulation and the metabolic syndrome following gestational diabetes. Diabetologia 2006:49(1):36-40. http://dx.doi.org/10.1007/ s00125-005-0058-6

39. Goueslard K, Cottenet J, Mariet AS, et al. Early cardiovascular events in women with a history of gestational diabetes mellitus. Cardiovasc Diabetol 2016;15(1):1-7. http://dx. doi.org/10.1186/s12933-016-0338-0

40. Foghsgaard $S$, Andreasen $C$, Vedtofte $L$, et al. Nonalcoholic fatty liver disease is prevalent in women with prior gestational diabetes mellitus and independently associated with insulin resistance and waist circumference. Diabetes Care 2017;40(1):109-16. http://dx.doi.org/10.2337/ dc16-1017

41. Dalfrà MG, Nicolucci A, Bisson T, Bonsembiante B, Lapolla A. Quality of life in pregnancy and post-partum: a study in diabetic patients. Qual Life Res 2012;21(2):291-8. http://dx.doi.org/10.1007/s11136-011-9940-5

42. Kolu P, Raitanen J, Rissanen P, Luoto R. Health care costs associated with gestational diabetes mellitus among high-risk women: results from a randomised trial. BMC Pregnancy Childbirth 2012;12. http://dx.doi.org/ 10.1186/1471-2393-12-71

43. Stedman $M$, Lunt $M$, Livingston $M$, et al. The costs of drug prescriptions for diabetes in the NHS. Lancet 2019;393(10168):226-7. http://dx.doi.org/10.1016/S0140-6736(18)33190-8

44. Hex N, Bartlett C, Wright D, Taylor M, Varley D. Estimating the current and future costs of type 1 and type 2 diabetes in the UK, including direct health costs and indirect societal and productivity costs. Diabet Med 2012;29(7):855-62. http://dx.doi.org/10.1111/j.1464-5491.2012.03698.x

45. Goueslard K, Cottenet J, Mariet AS, Sagot P, Petit JM, Quantin C. Early screening for type 2 diabetes following gestational diabetes mellitus in France: hardly any impact of the 2010 guidelines. Acta Diabetol 2017;54(7):645-51. http://dx.doi.org/10.1007/s00592-017-0986-x

46. Kim C, Bahman P, Burke R, et al. Missed opportunities for type 2 diabetes mellitus screening among women with a history of gestational diabetes mellitus. Am J Public Health 2006;96(9):1643-8. http://dx.doi.org/10.2105/AJPH.2005.065722

47. Kwong S, Mitchell RS, Senior PA, Chik CL. Postpartum diabetes screening: adherence rate and the performance of fasting plasma glucose versus oral glucose tolerance test. Diabetes Care 2009;32(12):2242-4. https://doi.org/10.2337/dc09-0900

48. Blatt AJ, Nakamoto JM, Kaufman HW. Gaps in diabetes screening during pregnancy and postpartum. Obstet Gynecol 2011;117(1):61-8. http://dx.doi.org/10.1097/AOG.0b013e3181fe424b

49. Dennison RA, Fox RA, Ward RJ, Griffin SJ, Usher-Smith JA. Women's views on screening for type 2 diabetes after gestational diabetes: a systematic review, qualitative synthesis and recommendations for increasing uptake. Diabet Med 2020;37(1):29-43. https://doi.org/ 10.1111/dme.14081

50. Peticca P, Shah BR, Shea A, et al. Clinical predictors for diabetes screening in the first year postpartum after gestational diabetes. Obstet Med 2014;7(3):116-20. http://dx.doi.org/10.1177/1753495X14528487

51. Benhalima K, Verstraete $S$, Muylle $F$, et al. Implementing a reminder system in the northern part of Belgium to stimulate postpartum screening for glucose intolerance in women with gestational diabetes: The "Sweet Pregnancy" Project. Int J Endocrinol 2017. http://dx.doi.org/ $10.1155 / 2017 / 3971914$

52. Halperin IJ, Sehgal P, Lowe J, Hladunewich M, Wong BM. Increasing timely postpartum oral glucose tolerance test completion in women with gestational diabetes: a quality-improvement initiative. Can J Diabetes 2015:39(6):451-6. http://dx.doi.org/10.1016/j.jcjd.2015.06.004

53. Jeppesen C, Kristensen JK, Ovesen P, Maindal HT. The forgotten risk? A systematic review of the effect of reminder systems for postpartum screening for type 2 diabetes in women with previous gestational diabetes. BMC Res Notes 2015;26(8):373. https://doi.org/10.1186/s13104015-1334-2 